\title{
Design of a 12 MW HTS Wind Power Generator including a Flux Pump Exciter
}

\author{
H. J. Sung, R. A. Badcock, B. S. Go, M. Park, I. K. Yu, and Z. Jiang
}

\begin{abstract}
A Flux Pump (FP) exciter injects DC current into the High Temperature Superconducting (HTS) field coils of an HTS rotating machine without a slip ring and current leads. When designing a large-scale HTS generator with integrated FP exciter, the coil inductance, field current, and time constant need to be optimized for better performance of the machine.

In this paper, a 12 MW HTS wind power generator with integrated FP exciter was designed. The essential parameters of a 12 MW HTS generator were optimised using the Taguchi method targeting the minimization of weight and volume of the generator, the length of HTS wire, and the inductance. Especially, the FP exciter was adopted for supplying DC current to the HTS field coils without the power supply and the slip ring. The magnetic field distribution was analysed using the 3D finite elements method. The induced DC current and charging and discharging times of the FP exciter were compared with the metal current leads for confirmation of the effectiveness of the FP exciter. The detailed results of the HTS generator design were discussed in detail.
\end{abstract}

Index Terms-Coated conductor, Flux pump, HTS dynamo, Modularization, Superconducting generator

\section{INTRODUCTION}

2 014 WAS a record year for the wind power industry as annual installations crossed the $50 \mathrm{GW}$ mark for the first time. Asia was the world's largest regional market for wind energy. The Chinese wind power market almost doubled its capacity from $62 \mathrm{GW}$ in 2011 to reach $114.6 \mathrm{GW}$ by the end of 2014. In Japan, the market saw new installations of 130.4 MW in 2014 to reach a cumulative capacity of 2,788.5 MW. Offshore wind power systems, in particular floating turbines, are technology that promises to achieve even greater capacity and is attractive in Korea and Japan. In Korea, the government had earlier proposed a strategy for offshore wind development with a target of $2.5 \mathrm{GW}$ by 2019 [1].

High Temperature Superconducting (HTS) generators are suitable for large-scale wind power systems because of their potential for significant reductions in volume and weight and

This work was supported by the Power Generation \& Electricity Delivery Core Technology Program of the Korea Institute of Energy Technology Evaluation and Planning (KETEP), granted financial resource from the Ministry of Trade, Industry \& Energy, Republic of Korea. (No. 20142020103560). (Corresponding author: I. K. Yu)

H. J. Sung, B. S. Go, M. Park, and I. K. Yu are with the Electrical Engineering Department, Changwon National University, Changwon-si, Rep. of Korea (e-mail: yuik@cwnu.ac.kr).

R. A. Badcock and Z. Jiang are with Robinson Research Institute, Victoria University of Wellington, PO Box 33436, New Zealand (e-mail: rod.badcock@vuw.ac.nz). an increased power density compared to conventional generators. Many researchers have tried to develop feasible HTS generator technology [2]-[7]. However, any large-scale HTS generator has its own set of problems such as the need for a huge vacuum vessel, and difficulty of repairing and maintaining the HTS coils.

A modularized $12 \mathrm{MW}$-class HTS generator is designed to mitigate the problems mentioned above. The pole is structurally separated through the modularization, and a Flux Pump (FP) based exciter was applied for removing the power supply and slip-ring in this study. The FP exciter eliminates the heat conduction path and thus reduces the ohmic dissipation between the cryostat wall and the power supply.

The targets for designing a 12 MW HTS generator are a smaller and lighter generator, a shorter total length of HTS wire, and lower inductance of the HTS field coil which affects charging and discharging time of induced DC field current by the FP exciter. A modified Taguchi method is employed to achieve these objectives. The magnetic field distribution is analysed using the 3D Finite Elements Method (FEM). Based on the designs of the generator and FP exciter, induced DC current value, together with charging and discharging times, are calculated. As a result, the charging and discharging times of $90 \%$ of saturation value are 4 days and 14.5 days which suggests the FP exciter can be applied to the wind turbine even when it stops and restarts. These results can be utilized to design a large-scale wind turbine.

\section{CONFIGURATION OF A 12 MW HTS GENERATOR WITH AN FP EXCITER}

Fig. 1 below illustrates all the parts of the modularized HTS generator with integrated FP exciter and detailed cross-section of a module.

The HTS generator consists of both rotor parts and stator parts. The rotor components are HTS field coils, modularized cryostats and support structure, and a rotor body. The stator components are comprised of stator teeth, copper stator coils, and generator gear to rotate the FP exciter. The materials of the rotor body, cryostat, and stator teeth are made of stainless steel to prevent iron losses. The magnetic shield is silicon laminated steel, which is used to protect electric devices.

The modularization of the generator enables a lower cryogenic volume, an easier repair, assembly, and maintenance of the HTS field coil. Specifically, if one HTS field coil fails during operation, other coils are not affected due to physical and electrical isolation. Modularization will be suitable for commercial mass production and will increase the 
(a)

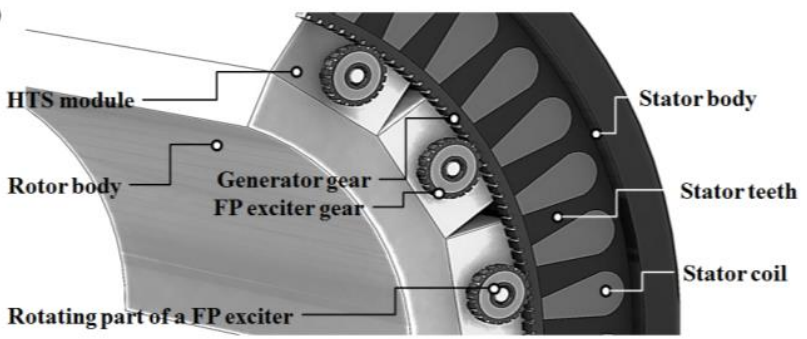

(b)

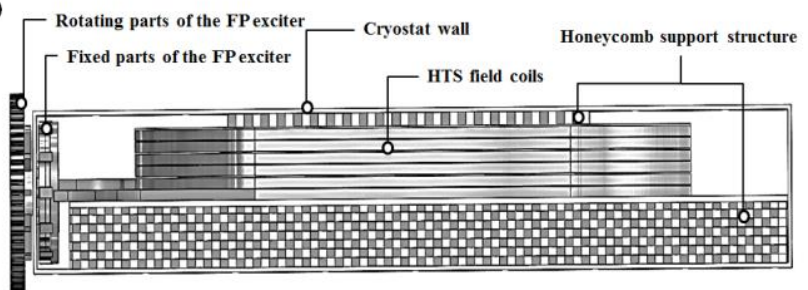

(c) FPexciter gear

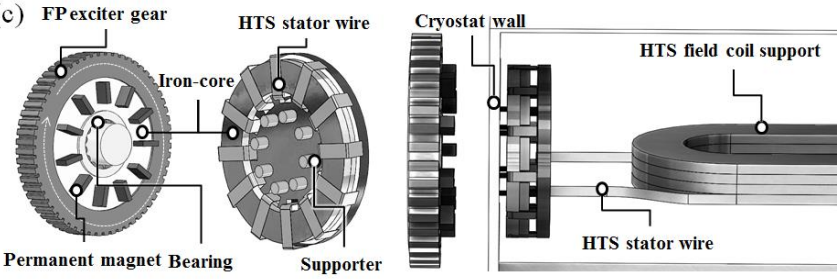

Fig. 1. (a) Whole configuration of the modularized HTS generator (b) A side view of a single module with FP exciter (c) Rotating and fixed parts of the FP exciter, and HTS stator connection with HTS field coils

operational availability of HTS generators in the wind turbine.

The FP exciters are applied to each module and classified by rotating and fixed parts as shown in Fig. 1(b). The rotating parts are permanent magnets, iron-shaft, iron-disk, and FP exciter gear at room temperature. These parts are rotated by interlocking gear teeth of the generator and FP exciter. The fixed parts include an HTS stator wire, iron-disk, iron-shaft, and iron-ring at low temperature. The fixed parts are located in the cryostat of the generator for directly connecting the HTS stator wire to the HTS field coil as shown in Fig. 1(c).

Excitation is via a rotating magnetic field (provided by permanent magnets) rotating past the HTS stator wire. When the magnetic flux of the magnets penetrates the HTS stator wire, a DC current is induced due to quasi-DC electro motive force (EMF) in the HTS wire, and which in turn energizes a HTS field coil [8].

\section{DESIGN OF THE 12 MW HTS GENERATOR WITH THE FP EXCITER}

\section{A. Design of the Generator using the Taguchi Method}

Before using the optimal method-modified Taguchi method-the fundamental specifications are defined and presented in Table I.

Rated output power is 12.3 MW including power losses such as ohmic loss, iron loss, and windage loss. The double pancake type HTS racetrack coils are wound using YBCO wire. The HTS wire is $12 \mathrm{~mm}$ width and $0.125 \mathrm{~mm}$ thick, including insulation. The stator winding has double-layered, distributed three-phase winding.
TABLE I

FUNDAMENTAL SPECIFICATIONS OF THE $12 \mathrm{MW}$ HTS GENERATOR

\begin{tabular}{|c|c|c|c|c|}
\hline \multicolumn{3}{|c|}{ Item } & \multicolumn{2}{|c|}{ Value } \\
\hline \multicolumn{3}{|l|}{ Rated output power } & \multicolumn{2}{|l|}{$12.3 \mathrm{MW}$} \\
\hline \multicolumn{3}{|c|}{ Rated line-to-line voltage } & \multicolumn{2}{|l|}{$6.6 \mathrm{kV}$} \\
\hline \multicolumn{3}{|c|}{ Rated armature current } & \multicolumn{2}{|l|}{$1.076 \mathrm{kA}$} \\
\hline \multicolumn{3}{|l|}{ Rated rotational speed } & \multicolumn{2}{|c|}{$8 \mathrm{rpm}$} \\
\hline \multicolumn{3}{|l|}{ Output torque } & \multicolumn{2}{|c|}{ 14.7 MNm } \\
\hline \multicolumn{3}{|l|}{ Operating temperature } & \multicolumn{2}{|l|}{$20 \mathrm{~K}$} \\
\hline \multicolumn{3}{|l|}{ Air-gap } & \multicolumn{2}{|l|}{$30 \mathrm{~mm}$} \\
\hline \multicolumn{3}{|c|}{ HTS wire type } & \multicolumn{2}{|c|}{ YBCO } \\
\hline \multicolumn{3}{|c|}{ No. of stator slots/phase/pole } & \multicolumn{2}{|c|}{2} \\
\hline \multicolumn{5}{|c|}{$\begin{array}{c}\text { TABLE II } \\
\text { CONTROL PARAMETERS AND LEVELS OF THE } 12 \mathrm{MW} \text { HTS GENERATORS }\end{array}$} \\
\hline Control parameters & $\begin{array}{l}\text { Control } \\
\text { symbol }\end{array}$ & Level 1 & Level 2 & Level 3 \\
\hline $\begin{array}{l}\text { No. of HTS field } \\
\text { coil layers per pole }\end{array}$ & A & 4 & 6 & 8 \\
\hline $\begin{array}{l}\text { No. of HTS field } \\
\text { coil turns per field } \\
\text { coil layer per pole }\end{array}$ & B & 500 & 750 & 1,000 \\
\hline $\begin{array}{l}\text { No. of stator coil } \\
\text { turns per slot }\end{array}$ & $\mathrm{C}$ & 20 & 25 & 30 \\
\hline No. of rotor poles & $\mathrm{D}$ & 18 & 24 & 30 \\
\hline
\end{tabular}

Based on these specifications, the modified Taguchi method is used to find the optimal design of the generator. The method is useful in finding optimal parameters and reduces the time needed for simulations [9]. In this paper, the targets of the generator design are a smaller and lighter generator, lower inductance, and a shorter total length of HTS wire. The smaller and lighter generator can reduce the construction costs. The cost of the HTS generator declines by the shorter length of HTS wire. The inductance of the HTS field coils is related with the saturation time of the DC field current of the FP exciter. The lower inductance helps the HTS generator including the FP exciter reach the rated output power quickly. The control parameters to reach these targets are shown in Table II.

The magnetic field and the size of the generator are significantly dictated to the output power of the generator. The HTS coil inductance is influenced by the magnetic field [10]. The control parameters in Table II adjust the magnetic field and the size of the generator. The variables of these control parameters have three levels. Therefore, the total number of simulations is 9 owing to orthogonal arrays in the Taguchi method [11].

One of the key features of the Taguchi method is the use of Signal-to-Noise (S/N) ratio to transform the performance or design characteristics in the optimization process. Three equations to calculate the $\mathrm{S} / \mathrm{N}$ ratio are expressed. In this paper, the $\mathrm{S} / \mathrm{N}$ ratios are calculated for the-smaller-the-better quality characteristics of the targets, as in (1).

$S N$ ratio $=10 \log \left(\frac{1}{n} \sum_{i=1}^{n} y_{i}^{2}\right)$

where, $y$ represents the values of the simulation results, and $n$ is the total number of simulations. $i$ is a type of the targets. 


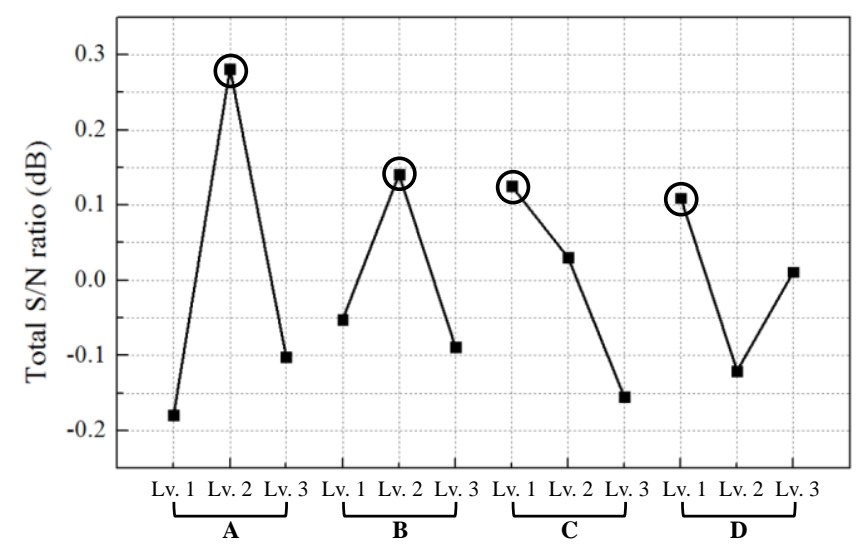

Fig. 2. Total S/N ratio of the control parameters. The largest value of total $\mathrm{SN}$ ratios at each factor is the optimal parameter.

Next, total $\mathrm{S} / \mathrm{N}$ ratios are estimated by using $\mathrm{Z}$ standardization and weight factor as (2) and (3).

$$
S N_{p}^{*}=\frac{S N_{p}-a v\left(S N_{p}\right)}{\operatorname{s.d}\left(S N_{p}\right)}
$$

Total $S N$ ratio $=\sum_{i=1}^{q} \omega_{i} S N_{i}^{*}(q=1,2,3)$

where, $S N_{p}$ is the $p$-th $\mathrm{SN}$ ratio, $a v\left(S N_{p}\right)$ is the average of the $\mathrm{SN}$ ratio, s.d( $\left.S N_{p}\right)$ is the standard deviation of the $\mathrm{SN}$ ratio, and $\omega_{i}$ is the weight factor of the $i$-th characteristics which represents the relative importance of the $i$-th characteristics. Therefore, the sum of the weight factors is 1. Each of the factors in the targets has the same value. More detailed formulas and theories about the Taguchi method are presented in [11]. Fig. 2 shows the calculation results according to the control parameters of the generator. The largest value of each control parameter is the optimal parameter for achieving the targets of the HTS generator. Using the optimal parameters, the HTS generator is re-simulated.

\section{B. Design of the FP Exciter}

The FP exciter is required to operate with a considerable air-gap between the rotating and fixed parts due to the requirement to bridge the cryostat wall. Therefore, to increase the magnetic flux density in the HTS stator wire for inducing DC current in the exciter, laminated silicon steel is used in the exciter magnetic circuit. The iron-shafts in the rotating and fixed parts enhance the magnetic circuit and allow magnetic flux to penetrate the HTS stator wire which has $12 \mathrm{~mm}$ width and $0.125 \mathrm{~mm}$ thickness.

The total diameter and the number of the permanent magnet poles depend on the size of module in the generator. The rotational speed of the exciter is calculated by considering the inner radius of the stator and outer radius of the exciter as shown in Fig. 3.

The number of HTS stator wires is decided after confirming how much EMF and DC current can be induced in a single HTS stator wire. The dimensions of the FP exciter are shown in Fig. 4.

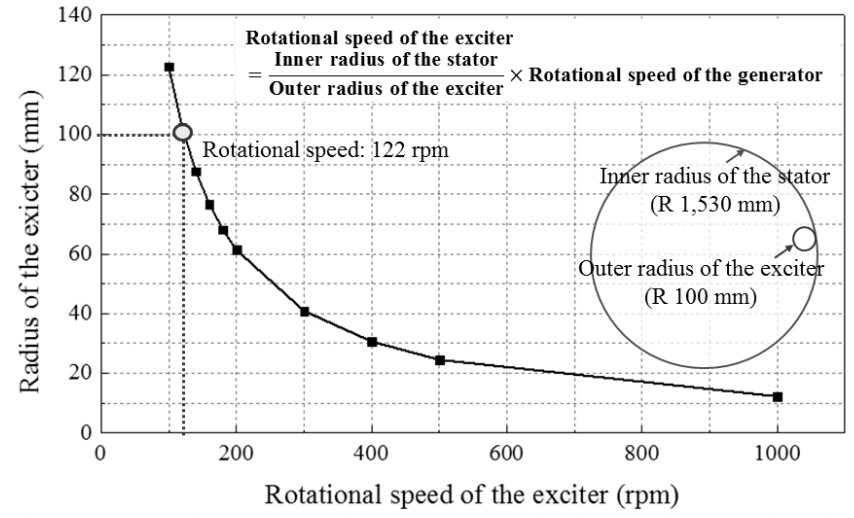

Fig. 3. The rotational speed of the exciter considering the inner radius of the stator and the outer radius of the exciter.

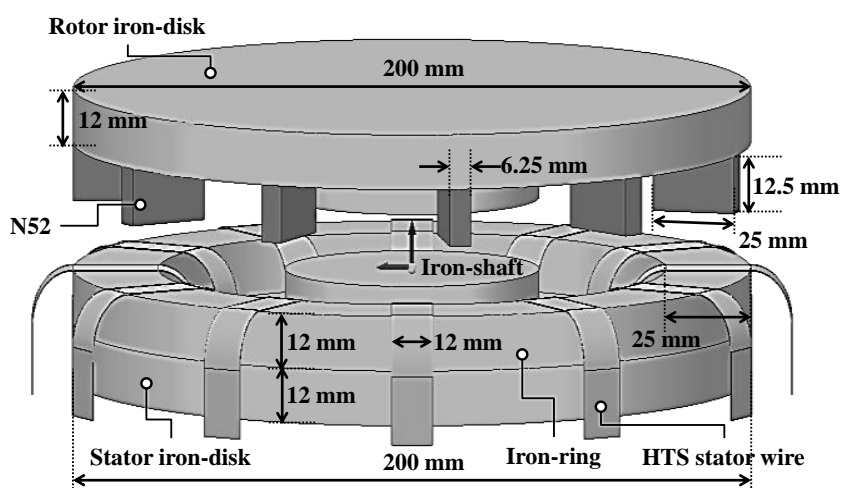

Fig. 4. Structure and dimensions of the FP exciter. The permanent magnets are located at the rotor part, and the HTS stator wires are placed at the stator part.

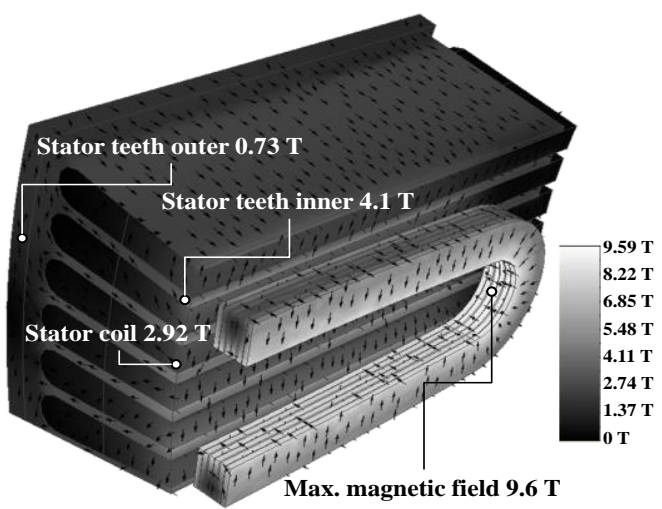

Fig. 5. Magnetic field distributions of 1/36 model of the $12 \mathrm{MW}$ HTS generator. The maximum magnetic field occurs at the curve of the HTS field coil, and the outside of the stator teeth is not saturated.

\section{ANALYSIS RESUlTS AND DisCUSSIONS}

\section{A. FEM Analysis Results}

The optimal design for the generator was analysed using a 3D FEM program. Fig. 5 illustrates the magnetic field distributions of the generator. The maximum and perpendicular magnetic fields are $9.6 \mathrm{~T}$ and $5.7 \mathrm{~T}$ at the HTS field coils. The DC field current is 313 A with $30 \%$ margin in which the current is determined by the properties of the HTS wire [12].

The magnetic flux density at the inside point of the stator teeth is $4.1 \mathrm{~T}$, which means the iron-core is saturated. 


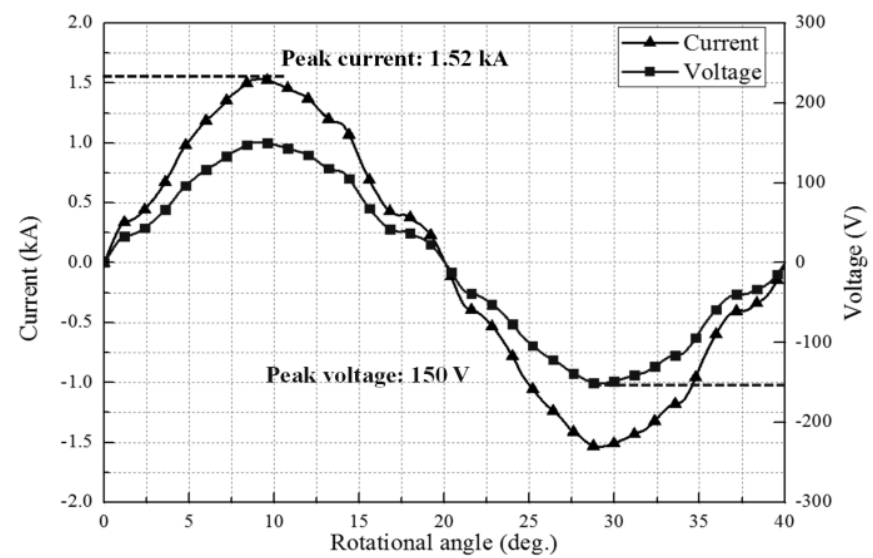

Fig. 6. Single phase rated output voltage and current of $1 / 36$ model of the generator. The generator produces three-phase electric power, and the power is controlled by a full-scale frequency converter which is connected to the generator.

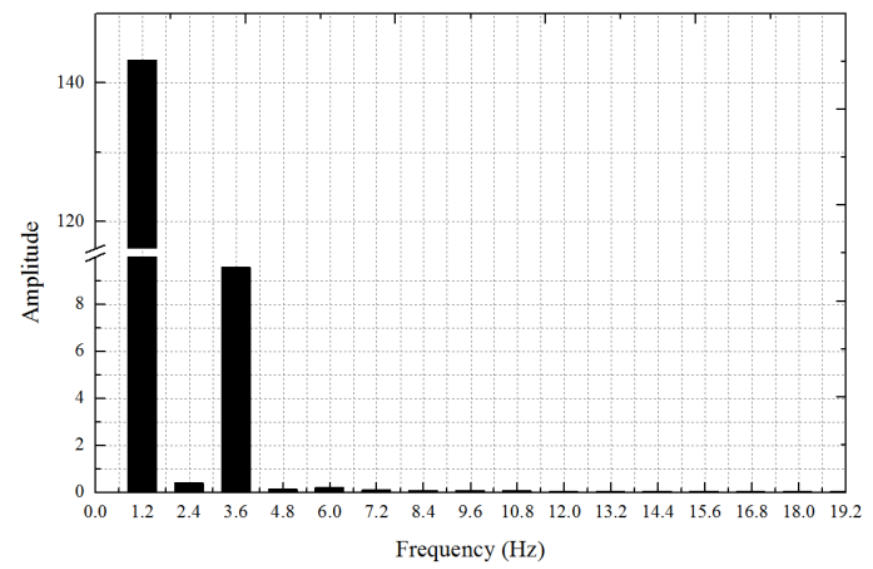

Fig. 7. Harmonic spectrum of the output voltage in the generator. The frequency of the generator is $1.2 \mathrm{~Hz}$ in which the number of the poles is 18 and the rotational speed is $8 \mathrm{rpm}$.

However, at the outside point of the stator teeth, the density is not saturated at $0.73 \mathrm{~T}$, which can help the magnetic flux flow along the core. Total loss of the generator considering iron loss and ohmic loss is $141 \mathrm{~kW}$. Rated output voltage or induced EMF and current are generated as shown in Fig. 6. In the IEEE standard, the Total Harmonic Distortion (THD) of line-to-line voltage in a synchronous machine must be less than 5\% [13], [14]. The voltage THD of $4.2 \%$ in the designed generator falls within the standard limit. Fig. 7 shows the harmonic spectrum of the output voltage in the generator.

Total diameter and effective length of the generator are $4 \mathrm{~m}$ and $2.2 \mathrm{~m}$ respectively. The weight of the generator excluding cover and the total length of HTS wire are 118 tons and 294 $\mathrm{km}$. When the structure of the modularization and the FP exciter are considered, the inductance per pole is $35.7 \mathrm{H}$.

The magnetic field distribution and magnetic flux directions of the FP exciter are shown in Fig. 8. The maximum magnetic field density of Neodymium permanent magnet (N52) is $1.4 \mathrm{~T}$. This flux can penetrate the HTS stator wire, as confirmed by the simulation result.

Based on the module size, the required number of permanent magnets is 11 for each FP exciter. The rotational speed of the exciter is $122 \mathrm{rpm}$ given by the gear ratio between
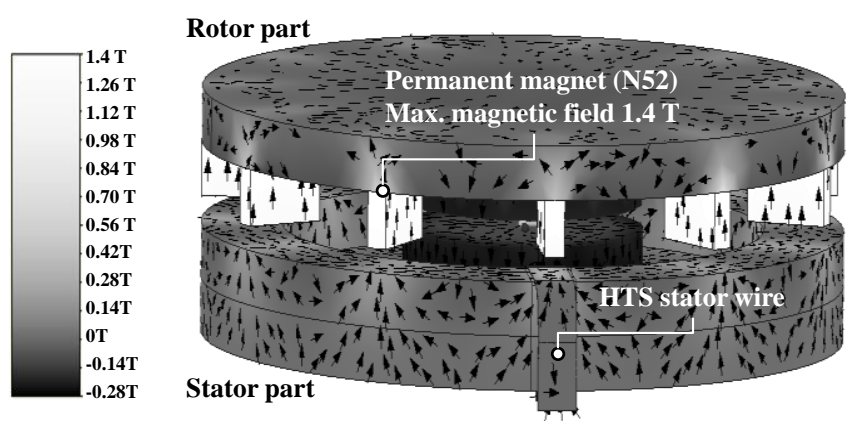

Fig. 8. Magnetic field distributions of the FP exciter. The magnetic flux of all magnets are in the same direction.

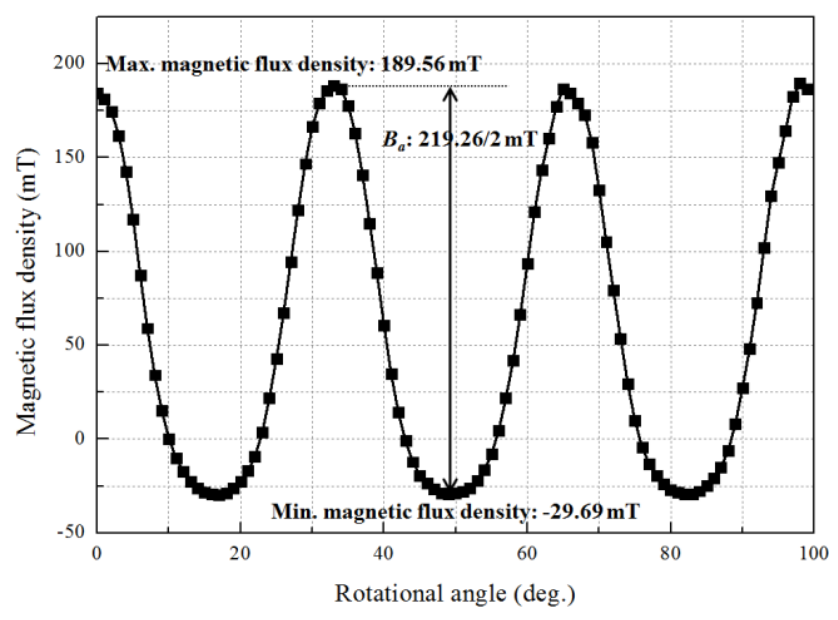

Fig. 9. Magnetic flux density wave depending on rotational angle of the permanent magnets at the HTS stator wire.

as the inner stators of the generator and the exciter. To calculate the pumping DC current from the exciter, we need to know the amplitude of the applied magnetic field on the HTS stator wire [8]. Therefore, the amplitudes of the maximum and minimum magnetic fields are illustrated in Fig. 9. The maximum magnetic field on the wire occurs when the permanent magnet is directly aligned with the centre of the stator wire, and the minimum magnetic field is achieved when the centre between adjoining magnets is directly lined up with the centre of the wire. The iron-loss of the fixed part at low temperature is $0.2 \mathrm{~W}$.

\section{B. Estimation of Pumping DC Current}

Previous publications have demonstrated operation of FP exciters. In particular, the dynamic resistance $\left(R_{d}\right)$ is critically important to operation and experimentally verified in a type-II superconductor with a time-varying magnetic field [8], [15], [16]. The equation for this resistance is given as

$R_{d}=\frac{4 a l_{e f f} f}{I_{c o}}\left(B_{a}+\frac{B_{a}^{2}}{B_{o}}\right), \quad$ for $B_{a} \gg>2 B_{t h}$

where, half the amplitude of the maximum and minimum magnetic field is expressed as $B_{a} .2 a$ and $l_{\text {eff }}$ are the effective interaction width and length of the time-varying magnetic 

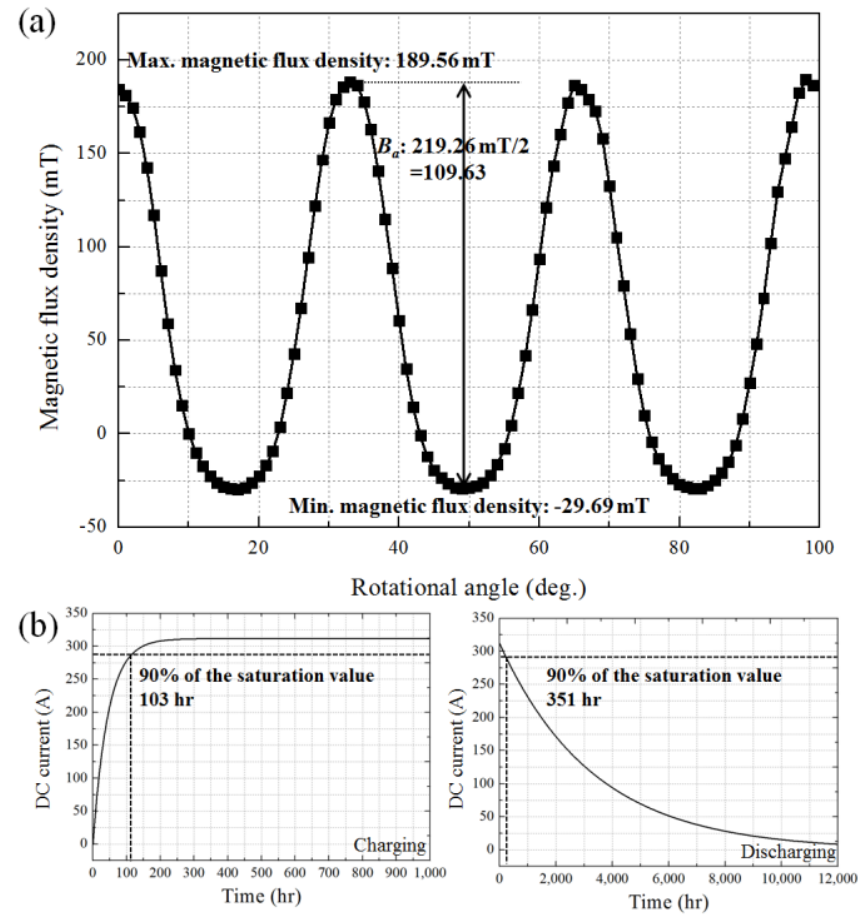

Fig. 10. (a) EMF at the HTS stator wire. The EMF of the FP exciter is not symmetric between positive and negative factors, indicating the EMF is a DC element. (b) Charging time to saturate the pumping DC current and discharging time to completely dissipate the current.

field on the wire. $I_{c o}$ and $B_{o}$ are the parameters from the Kim model [17]. $B_{t h}$ is the threshold magnetic field [18].

The key parameters for calculating DC current are opencircuit DC voltage $\left(V_{o c}\right)$ or EMF, dynamic resistance, joint resistances for connecting HTS stator wire to the HTS field coil, and inductance $(L)$ of the HTS field coil. In this paper, joint resistance $\left(R_{J}\right)$ of each connection is given as $1 \mu \Omega$. The open-circuit DC voltage on the wire is generated by the magnets as in Fig. 10(a), and it is integrated via the inductance of the connected HTS field coil. Therefore, the pumping DC current can be estimated as,

$$
I(t)=\frac{V_{o c}}{R}\left(1-e^{-\frac{R}{L} t}\right)
$$

where, $R$ is the sum of $R_{d}$ and $R_{J}$. Fig. 10(b) shows the charging and discharging time of the pumping DC current when the HTS stator wire is connected with the field coil. In the case of charging time, the time constant considers $L$ and $R$. However, the discharging time considers just $L$ and $R_{J}$ because rotation has stopped, which means $R_{d}$ does not occur. The combination of HTS stator wires means that the wires are connected in series or parallel, and the pumping DC current is reached to the DC field current of the generator. In this paper, the parallel of 6 and the series of 10 are connected between the exciter and HTS field coil. The charging and discharging times with the combination of $90 \%$ of saturation value are 4 days and 14.5 days. In case of metal current leads, the charging and discharging times of the leads are 3 days and 4 hours.
When the generators with FP exciter and without FP exciter (with the current leads) are compared, the starting times to generate the power are almost the same. If the generator is stopped for 4 days, the DC current of the generator with FP exciter is not discharged to 0 . However, in the case of the metal current leads, the DC current is discharged for 4 days. It means that the wind turbine with the current leads requires 3 days for recharging the DC field current.

Total loss of the module with the FP exciter is 25.2 $\mathrm{W} /$ module. In the case of the metal current leads, the loss is $27.5 \mathrm{~W} /$ module. Therefore, the total loss of the modules with FP exciter is $41.4 \mathrm{~W} / 18$ modules which is much lower than the loss of the modules without FP exciter.

\section{CONCLUSIONS}

In this paper, the design parameters of a 12 MW HTS wind power generator including a flux pump exciter have been proposed.

As a result, the volume and weight of the 12 MW HTS generator, the total length of HTS wire, and inductance per pole are $11.2 \mathrm{~m}^{3}, 118$ tons, $294 \mathrm{~km}$, and $35.7 \mathrm{H}$, respectively. Therefore, the generator weight is approximately half that of a conventional generator. The charging and discharging times of the generator with FP exciter are 4 days and 14.5 days, respectively. Whereas the generator with metal current leads are 3 days and 4 hours for charging and discharging. In the case of the metal current leads, the DC current is discharged for 4 days. It means that the generator with the current leads requires 3 more days for recharging the DC current again. Therefore, the FP exciter is possibly applied to wind turbines for not only extending discharging time but also removing power supply. The results will be effectively utilized to design large-scale HTS wind power generators with FP exciters.

\section{REFERENCES}

[1] Global Wind Energy Council, Global Wind Report 2014. Brussels, Belgium, 2015.

[2] H. J. Sung, G. H. Kim, K. Kim, S. J. Jung, M. Park, I. K. Yu, Y. G. Kim, H. Lee, and A. R. Kim, "Practical design of a 10 MW superconducting wind power generator considering weight issue," IEEE Trans. Appl. Supercond., vol. 23, no. 3, Jun. 2013, Art. ID. 5201805.

[3] H. Karmaker, M. Ho, E. Chen, and D. Kulkarni, "Direct drive HTS wind generator design for commercial applications," Electrical Machines., 2014, pp. 491-495.

[4] HORIZON 2020, Thyborøn, Denmark. EcoSwing-World's First Demonstration of a 3.6 MW Low-Cost Lightweight DD Superconducting Generator on a Wind Turbine. (2015) [Online]. Available: http://cordis.europa.eu/project/rcn/195203_en.html, Accessed on 01 Mar. 2015.

[5] A. B. Abrahamsen, N. Mijatovic, E. Seiler, T Zirngibl, C. Træholt, P. B. Nørg ard, N. F. Pedersen, N. H. Andersen and J. Østerg ard, "Superconducting wind turbine generators," Sci. Technol., vol. 23, 2010, Art. ID 034019.

[6] R. Shafaie and M. Kalantar, "Design of a 10-MW-class wind turbine HTS synchronous generator with optimized field winding," IEEE Trans. Appl. Supercond., vol. 23, no. 4, Aug. 2013, Art. ID 5202307.

[7] S. Fukui, J. Ogawa, T. Sato, O. Tsukamoto, N. Kashima, and S. Nagaya, "Study of $10 \mathrm{MW}$-class wind turbine synchronous generators with HTS field windings," IEEE Trans. Appl. Supercond., vol. 21,no. 3, pp. 11511154, Jun. 2011.

[8] Z. Jiang, K. Hamilton, N. Amemiya, R. A. Badcock, and C. W. Bumby, "Dynamic resistance of a high-Tc superconducting flux pump," Applied Physics Letters., vol. 105, no. 11, Sep. 2014, Art. ID. 112601. 
[9] H. J. Sung, G. H. Kim, K. Kim, M. Park, I. K. Yu, and J. Y. Kim, "Design and comparative analysis of $10 \mathrm{MW}$ class superconducting wind power generators according to different types of superconducting wires," Physica C., vol. 494, pp. 255-261, Nov. 2013.

[10] T.J.E Miller and A. Hughes, "Design and comparative analysis of 10 MW class superconducting wind power generators according to different types of superconducting wires," IEE Proceedings., vol. 124, pp. 127132, Feb. 1997.

[11] B. Y. Yang, K. Y. Hwang, S. B. Rhee, D. K. Kim, and B. I. Kwon, "Optimization of novel flux barrier in interior permanent magnet-type brushless dc motor based on modified Taguchi method," Applied Physics Letters., no. 105, Feb. 2009.

[12] SuperPower Inc., Schenectady, NY, USA. SuperPower 2G HTS wire specifications. (2014) [Online]. Available: http://www.superpowerinc.com/system/files/SP_2G+Wire+Spec+Sheet_2014_web_v1_0.pdf.

[13] IEEE, 1547-2003-IEEE Standard for Interconnecting Distributed Resources with Electric Power Systems, 2003, pp. 13.

[14] H. J. Sung, M. Park, and I. K. Yu, "Designs of $10 \mathrm{MW}$ Air-core and Iron-core HTS Wind Power Generators," JEET, vol. 10, Mar. 2015.

[15] M. Iwakuma, K. Toyota, M. Nigo, and T. Kiss, "AC loss properties of YBCO superconducting tapes fabricated by IBAD-PLD technique," Physica C., vol. 412-414, pp. 983-991, Oct. 2004.

[16] Z. Jiang, C. W. Bumby, R. A. Badcock, H. J. Sung, N. J. Long, and N. Amemiya, "Impact of flux gap upon dynamic resistance of a rotating HTS flux pump," Superconductor Science and Technology., to be published.

[17] Y. B. Kim, C. F. Hempstead, and A. R. Strnad, "Critical persistent currents in hard superconductors," Phys. Rev. Lett., vol. 9, no. 7, pp. 255-261, Oct. 1962.

[18] M. P. Oomen, J. Rieger, M. Leghissa, B. ten Haken. And H. H. J. ten Kate., "Dynamic resistance in a slab-like superconductor with $\mathrm{J}_{\mathrm{c}}(\mathrm{B})$ dependence," Supercond. Sci. Technol., vol. 12, pp. 382-387, 1999. 